\title{
Conflict Balanced Design for the Evaluation System of University Research Achievements
}

\author{
Hongzhuan Chen, Liangliang Shu \\ College of Economics and Management, Nanjing University of Aeronautics and Astronautics, Nanjing China \\ Email: Chz-hhu@163.com, shuliangliang@163.com
}

Received 2012

\begin{abstract}
Scientific research evaluation has an important guiding significance to university scientific research work. Based on conflict analysis model, it studies the strategies and preferences among the government, universities and scientists in the scientific research evaluation mechanism. It builds a conflict analysis model of three players and gives all possible equilibrium situations. The paper also analyzes the characteristics analysis of each equilibrium situation, it finds out the Pareto optimal situation of scientific research evaluation. The article provides guidance for the establishment of the evaluation system of university research.
\end{abstract}

Keywords: Scientific Research Evaluation; Confict; Equilibrium

\section{Introduction}

In our country, the group of researchers such as teachers in many research universities is one of the important subjects to undertake development and research of the social academy. Therefore, academy naturally becomes a key factor and the core of the university. Academic evaluation is the judgment and affirmation of the intrinsic value of the academic achievements. For universities, it is the wind vane of academic development direction. It directly determines the value orientation and working key for researchers. With the increase of researchers and institutions, our country invests huge amounts of money for scientific research every year. However, it is hard to evaluate the academic level and quality of scientific research (Wei Zhang, 2007), as we investing huge scientific research funds. In the universities of our country, a large number of scientific and technological achievements pass the assessment every year. However, the achievements of scientific research which meet the needs of the community and can be translated into practical productive forces and products are insufficienct. To sum up, through continuous reform, the evaluation index system, means and ways of scientific research achievement obtained comprehensive progress than before, starting from the system environment to specific systems and measures, and even legal protection, the implementation process, being more comprehensive, systemic. These methods provide the basis and norms for us to make some evaluation. They also provide a platform for the evaluation of academy achievements (Yuqing Ceng, 2006). During the process university research evaluation system, there are varying degrees of judgment and understanding of conflicts among various interest groups in some aspects such as the quality of the research results, quantity and efficiency. It is difficult to meet the requirement of suitability, fairness, impartiality in the evaluation system of university research achievements. It affects the stability and development of scientific research in universities (Ying Zhou, 2003). To resolve conflict, ensuring the overall interests and long-term stability of universities, we use the conflict analysis theory to analyze the conflict in the university research evaluation system and its stability to provide a useful reference for the evaluation system of university research.

\section{Theory of Conflict Analysis}

Conflict analysis is a conflict analysis strategy presented by Fraser and Hipel in 1980s. It is a decision analysis method which focuses on solving social disputes. Conflict analysis aims to coordinate the contradiction of each participant in the conflict and put forward finally expedient solution. Conflict analysis model can be abbreviated as: $\mathrm{G}=\{\mathrm{N}, \mathrm{Q}, \mathrm{V}, \mathrm{UI}\}$. $\mathrm{N}$ is the player, namely the conflict subject. Q is all possible situations set under the current conflict model. They are represented by $0-1$ sequence and changed a binary number which corresponded by each situation into a decimal. $\mathrm{V}$ is the order set which represented player's preference to feasible situation. It is the optimal vector. UI is the set of unilateral improvements for all the players on their respective preference order of each element. The process of conflict analysis method is formed by two components modeling and stability analysis. Its processes are as follows:

Conflict analysis method starts from the analysis of the situation's stability. For a conflict situation, we need to consider whether multiple players in a pass to leave the current scheme can achieve better situation; Whether the last project cooperating with other players and partners to benefit is worth; How will the other players face the council of human movement and anti-movement in the conflict; All above information will be examined as the results of a conflict.

\section{Establishing of the Conflict Model}

\section{Conflict Players}

The evaluation system of university scientific research achievement contains two kinds of stakeholders, universities and researchers. However, the government also playes a great role in China's current of university research evaluation system 
guided by the government. The relationship among these three game subjects shown in Figure 2.

It can be seen from Figure 2, the government research department's encouragement to the researchers is a strong incentive, and the university's encouragement to the researchers is a weak incentive. This double game equilibrium is favorable for the dedication and diligence of researchers. It is necessary for the government research department reforms the current research project funding management system and achievements assessment system, in order to mobilize the enthusiasm of the researchers and stimulate the creativity of researchers. Therefore, in the conflict model of university research evaluation system, there are three major decision makers, namely, researcher, university and government.

\section{Strategy of Playerss}

The current studies of college scientific research achievement evaluation are mainly focused on the importance of quality and quantity in college scientific achievements evaluation. The results of these studies are mainly embodied in the scientific research achievement evaluation index system, as well as the qualitative evaluation and quantitative evaluation of research. Quite a few scholars advocate that the evaluation of university scientific research achievement should emphasize on quality of the achievement, and support qualitative evaluation. Qualitative evaluation seems to be more close to the characteristics of evaluation objects, and can reveal the value scientific research achievements better. The evaluation based on university scientific research achievement evaluation criteria seems to put emphasize on both the output of scientific research activities and its quality superficially. In fact the evaluation of scientific research achievements biases the pursuit of quantity, and ignore the quality. It makes scientific research activities more and more away from its own laws, which pushes academic morality level falling, and academic value depreciated causing certain impact on teaching level in universities. However, the humanities and social sciences can't provide the identification methods as clear as natural science. Even in the presence of social effect, it is difficult to use digital display. Along with the reform of evaluation system of scientific research, a simple method of quantification evaluation attracts considerable attention. As Deng Yi said in "Analysis of the university research quantitive evaluation" that academic quantization is not only possible but also necessary. The fundamental purpose of academic quantization is not a ' final judgment' of the academic research ability of an individual or a group, but an opportunity for potential researchers standing out (Yi Deng, 2006). Quantitative evaluation method has great practical value because it is flexible, objective, easy to be operated and it can get an objective outcome based on the statistics, metrology ,the given parameters and other software,

The index system of university scientific research achievement evaluation is a wind vane for wind researchers in universities (Junping Qiu, 2007). The operability of qualitative evaluation is not strong, and the subjectivity is outstanding. Although the quantity is important, the quality is more important. The quality can easily be ignored once the quantity is pushed to the top position. As the objective data cannot reflect the abstraction of scientific research, quantitative evaluation cannot guarantee that the data is effective to scientific research evaluation. In order to compensate evaluation problems, appropriate quantitative indicators should be introduced in the index system scientific research achievement evaluation. It plays a role of supplement and supervision in qualitative evaluation, so that the effectiveness of the scientific research evaluation index system can be improved and perfected.

In addition, the economic benefit of scientific research is an important indicator of universities and its research outcome. At present, university scientific research evaluation system focus on the pursuit of academic benefit, pays little attention to the actual benefit, especially the transformation from intellectual property to economic achievements. With the further development of economy, science and technology system reform, considering the economic benefit of scientific research when designing the evaluation system of college scientific research achievemenst is not only beneficial to the improvement of scientific research management, but also conducive to the acceleration of the popularization and application of research results, promoting the rapid transformation into enormous material strength, which can improve the scientific research work efficiency. Therefore, the conflict strategies of the three main decision makers are respectively: Researcher: A-- focus on the quality of scientific research; B-- focus on the quantity of scientific research ; C--focus on the social benefits of scientific research.

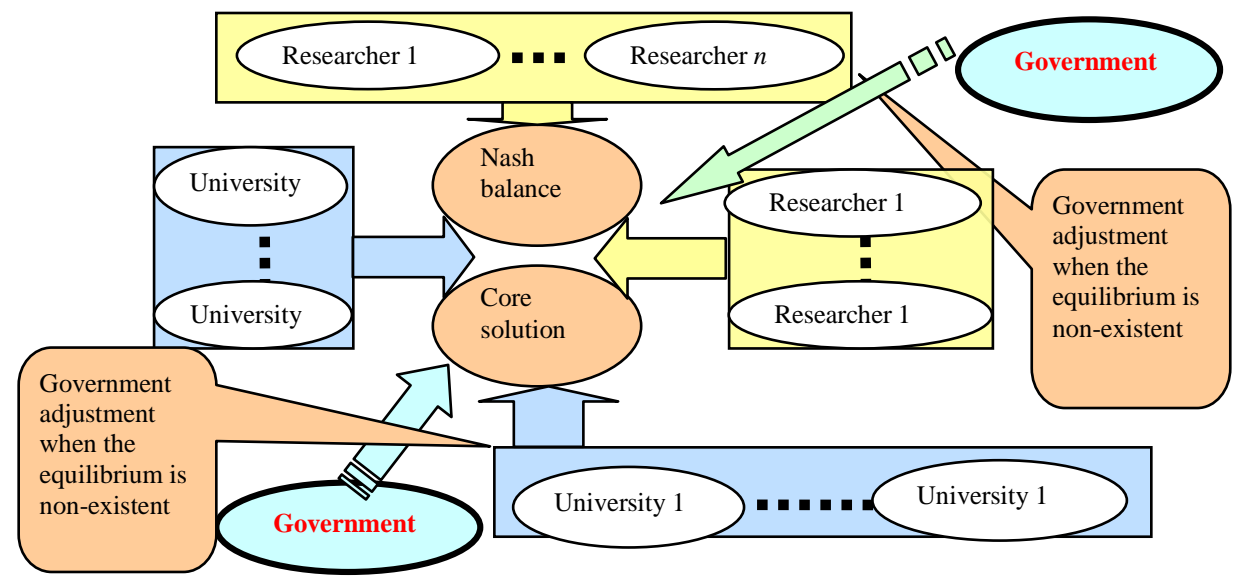

Figure 2.

The game relationship among stakeholders in university research evaluation system. 
University: D-- focus on the quality of scientific research; E-- focus on the quantity of scientific research ; F--focus on the social benefits of scientific research.

Government: G--use peer review, focus on quality, take incentive measures to the person who improving the quality of scientific research achievement; H--focus on the effect of scientific research, take incentive measures to the person who improving the social benefit of scientific research achievement.

In the conflict, each player can choose strategies according to other participants' measure. When every participant has selected a plan, the situation of the conflict is called a state. Theoretically, there exists $2^{3+3+2}=256$ states in this conflict, in fact many states is not possible. After such a simplify procedures to states, 30 possible states are obtained and shown in Table 1.

\section{Preference Analysis}

For researcher, the selected strategies more than school or government requirements is better, in other words, On the basis of having more strategies, researcher prefers the university or government has less requirements. For the three strategies, according to the priority is as $A>B>C$.

For university, the selected strategies less than researcher's strategies is better, in other words, On the basis of having less strategies, university prefers the researcher has more strategies. For the three strategies, according to the priority is as $F>D>E$.

For government, it pays more attention to the social benefit of the scientific research achievements than the quality. So according to the priority, is as $H>G$.
According to the parties' subjective desire and interest principle, we use decimal code indicating states in the conflict, the left is the most preferred, and the right is the least preferred. So the preferred vectors of player in the conflict is obtained and shown in Table 2.

\section{Stability Analysis}

For player $i$, consider the state $\mathrm{q}$, there are four possible stabilities in the conflict model:

(1) Reasonable type $(r)$ : If there is no UI for $q, q$ is called the reasonable and stable state, recorded as $r$.

(2) Not stable $(u)$ : There are at least one $U I$, and won't be hindered by other participants' reliable actions.

(3) Punishment type (s): If $q$ exists UI state $q$, and for other participants $j(j \neq i), q$ also exists UI state $q$, For player $i, q$ doesn't better than q, this is called a continuity punishment of $q$ UI state $q$. If for player $i$, all UI states of state $\mathrm{q}$ have continuous punishment, and state $q$ is called as a continuity punishment stable state of the player $i$, recorded as $s$.

(4) The same time stable (1): Consider the non-stability state $q$, if $q$ is also unstable for another player $j$, UI state $a_{i}$ (for player $i$ ) and $b_{j}$ (for player $j$ ) of the state $q$ produce a state $\mathrm{p}_{0}=\left(\mathrm{a}_{\mathrm{i}}+\mathrm{b}_{\mathrm{j}}-\mathrm{q}\right)$, for player $i$, p0 is not better than $q$, and this is called as state $a_{i}$ of $q$ existing a simultaneous punishment for player $i$.If for player $i$, all UI states of $\mathrm{q}$ have the same time punishment, and state $\mathrm{q}$ is called as the same time punishing stable state for player $i$, recorded as $l$.

For each player, if q belongs to $r, s$ or $u$, and q is global stable state, recorded as E. Table $\mathbf{3}$ shows stability analysis for all states in Table 2.

Table 1.

Feasible situation of university scientific research achievement evaluation system conflict model.

\begin{tabular}{|c|c|c|c|c|c|c|c|c|c|c|c|c|c|c|c|c|c|c|c|c|c|c|c|c|c|c|c|c|c|c|c|}
\hline Player & Strategy & & & & & & & & & & & & & & Fea & ssible & situc & ation & & & & & & & & & & & & & \\
\hline \multirow{2}{*}{1} & A & 1 & 1 & 0 & 0 & 0 & 0 & 0 & 0 & 0 & 0 & 0 & 0 & 0 & 0 & 1 & 1 & 1 & 1 & 1 & 1 & 1 & 1 & 1 & 1 & 1 & 1 & 1 & 1 & 1 & 1 \\
\hline & $\mathrm{C}$ & 0 & 0 & 0 & 1 & 1 & 0 & 1 & 1 & 0 & 1 & 1 & 0 & 1 & 1 & 0 & 0 & 1 & 1 & 0 & 0 & 1 & 1 & 0 & 0 & 1 & 1 & 0 & 0 & 1 & 1 \\
\hline \multirow{3}{*}{2} & $\mathrm{D}$ & 1 & 1 & 0 & 0 & 0 & 1 & 1 & 1 & 0 & 0 & 0 & 1 & 1 & 1 & 0 & 0 & 0 & 0 & 1 & 1 & 1 & 1 & 0 & 0 & 0 & 0 & 1 & 1 & 1 & 1 \\
\hline & $\mathrm{E}$ & 0 & 1 & 0 & 0 & 0 & 0 & 0 & 0 & 1 & 1 & 1 & 1 & 1 & 1 & 0 & 0 & 0 & 0 & 0 & 0 & 0 & 0 & 1 & 1 & 1 & 1 & 1 & 1 & 1 & 1 \\
\hline & $\mathrm{F}$ & 0 & 0 & 1 & 1 & 1 & 1 & 1 & 1 & 1 & 1 & 1 & 1 & 1 & 1 & 1 & 1 & 1 & 1 & 1 & 1 & 1 & 1 & 1 & 1 & 1 & 1 & 1 & 1 & 1 & 1 \\
\hline \multirow{2}{*}{3} & $\mathrm{G}$ & 1 & 1 & 0 & 0 & 0 & 0 & 0 & 0 & 0 & 0 & 0 & 0 & 0 & 0 & 1 & 1 & 1 & 1 & 1 & 1 & 1 & 1 & 1 & 1 & 1 & 1 & 1 & 1 & 1 & 1 \\
\hline & $\mathrm{H}$ & 0 & 0 & 1 & 1 & 1 & 1 & 1 & 1 & 1 & 1 & 1 & 1 & 1 & 1 & 1 & 1 & 1 & 1 & 1 & 1 & 1 & 1 & 1 & 1 & 1 & 1 & 1 & 1 & 1 & 1 \\
\hline \multicolumn{2}{|c|}{ decimal } & 73 & 91 & 162 & 164 & 166 & 170 & 172 & 174 & 178 & 180 & 182 & 186 & 188 & 190 & 225 & 227 & 229 & 231 & 233 & 235 & 237 & 239 & 241 & 243 & 245 & 247 & 249 & 251 & 253 & 255 \\
\hline
\end{tabular}

Table 2.

Preferred vector of players.

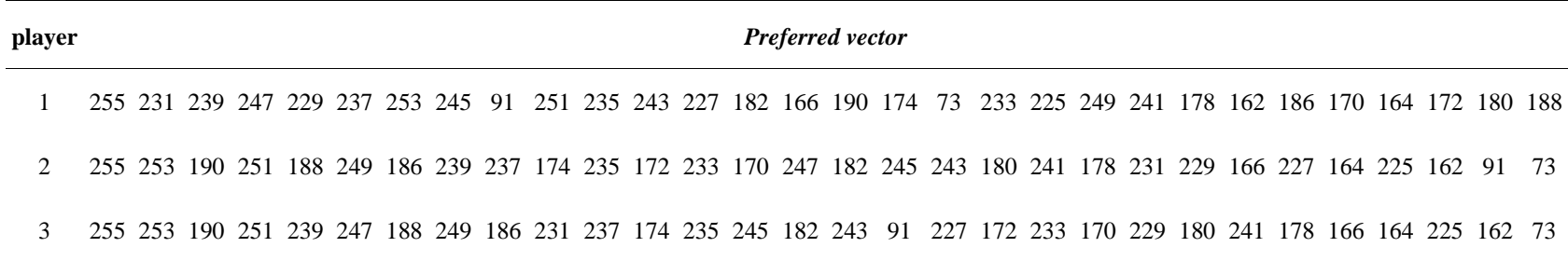


Table 3.

Stability analysis table.

\begin{tabular}{|c|c|c|c|c|c|c|c|c|c|c|c|c|c|c|c|c|c|c|c|c|c|c|c|c|c|c|c|c|c|c|c|}
\hline player & & $\mathrm{N}$ & $\mathrm{N}$ & $\mathrm{E}$ & $\mathrm{N}$ & $\mathrm{N}$ & $\mathrm{N}$ & $\mathrm{N}$ & $\mathrm{N}$ & $\mathrm{E}$ & $\mathrm{N}$ & $\mathrm{N}$ & $\mathrm{N}$ & $\mathrm{N}$ & $\mathrm{N}$ & $\mathrm{N}$ & $\mathrm{E}$ & $\mathrm{N}$ & $\mathrm{E}$ & $\mathrm{N}$ & $\mathrm{N}$ & $\mathrm{N}$ & $\mathrm{N}$ & $\mathrm{N}$ & $\mathrm{N}$ & $\mathrm{N}$ & $\mathrm{N}$ & $\mathrm{N}$ & $\mathrm{N}$ & $\mathrm{N}$ & $\mathrm{N}$ \\
\hline \multirow{4}{*}{1} & $\mathrm{a}$ & $\mathrm{r}$ & $\mathrm{r}$ & $r$ & $\mathrm{r}$ & $\mathrm{u}$ & $\mathrm{u}$ & $\mathrm{u}$ & $\mathrm{s}$ & $\mathrm{r}$ & $\mathrm{u}$ & $\mathrm{u}$ & $\mathrm{u}$ & $\mathrm{u}$ & $\mathrm{r}$ & $\mathrm{r}$ & $r$ & $\mathrm{r}$ & $\mathrm{r}$ & $\mathrm{u}$ & $\mathrm{u}$ & $\mathrm{u}$ & $\mathrm{u}$ & $\mathrm{u}$ & $\mathrm{u}$ & $\mathrm{u}$ & $\mathrm{u}$ & $\mathrm{u}$ & $\mathrm{u}$ & $\mathrm{u}$ & $\mathrm{u}$ \\
\hline & $\mathrm{b}$ & 231 & 239 & 255 & 247 & 229 & 237 & 253 & 245 & 91 & 251 & 235 & 243 & 227 & 182 & 166 & 190 & 174 & 73 & 233 & 225 & 249 & 241 & 178 & 162 & 186 & 170 & 164 & 172 & 180 & 188 \\
\hline & c & & & & & 231 & 239 & 255 & 247 & & 255 & 239 & 247 & 231 & & & & & & 235 & 229 & 255 & 247 & 182 & 166 & 190 & 174 & 166 & 174 & 182 & 190 \\
\hline & a & $\mathrm{r}$ & $\mathrm{r}$ & $\mathrm{r}$ & $\mathrm{r}$ & r & $\mathrm{r}$ & $\mathrm{r}$ & $\mathrm{u}$ & s & $\mathrm{u}$ & $\mathrm{u}$ & s & $\mathrm{s}$ & $\mathrm{s}$ & $\mathrm{u}$ & s & $\mathrm{s}$ & $\mathrm{u}$ & s & $\mathrm{u}$ & $\mathrm{s}$ & $\mathrm{u}$ & $\mathrm{s}$ & $\mathrm{s}$ & $\mathrm{u}$ & $\mathrm{s}$ & $\mathrm{s}$ & $\mathrm{s}$ & r & r \\
\hline \multirow[t]{3}{*}{2} & b & 255 & 253 & 190 & 251 & 188 & 249 & 186 & 239 & 237 & 174 & 235 & 172 & 233 & 170 & 247 & 182 & 245 & 243 & 180 & 241 & 178 & 231 & 229 & 166 & 227 & 164 & 225 & 162 & 91 & 73 \\
\hline & c & & & & & & & & 255 & 253 & 190 & 251 & 188 & 249 & 186 & 255 & 190 & 253 & 251 & 188 & 249 & 186 & 255 & 253 & 190 & 251 & 188 & 249 & 186 & & \\
\hline & $\mathrm{a}$ & $r$ & r & r & $r$ & $r$ & $\mathrm{r}$ & $r$ & $r$ & $r$ & $\mathrm{r}$ & $\mathrm{r}$ & $r$ & $r$ & r & $\mathrm{r}$ & $r$ & $r$ & $r$ & r & $\mathrm{r}$ & r & $r$ & r & $r$ & $r$ & $r$ & $\mathrm{r}$ & r & r & $r$ \\
\hline \multirow[t]{2}{*}{3} & b & 255 & 253 & 190 & 251 & 239 & 247 & 188 & 249 & 186 & 231 & 237 & 174 & 235 & 245 & 182 & 243 & 91 & 227 & 172 & 233 & 170 & 229 & 180 & 241 & 178 & 166 & 164 & 225 & 162 & 73 \\
\hline & C & & & & & & & & & & & & & & & & & & & & & & & & & & & & & & \\
\hline
\end{tabular}

(Here a represents policymakers stability, b represents the preferred vector of players ( suppliers ), c represents unilateral improvement.)

\section{Result Analysis}

From Table 3, we can see this conflict model has four stable solutions. The situation 255 shows that considering the quality, quantity of scientific research and social benefits caused by the quality and quantity, government will take positive incentives for researchers and schools. When researchers, schools and government build evaluation system of university research achievements, this is the Pareto equilibrium solution established by three sides. The situation 91 has the following meanings. When researchers, schools and government build evaluation system of university research achievements, not considering social benefits, government only encouraging the quality of scientific research can promote researchers and schools considering scientific research to consider the quality of the scientific achievement and efficiency. The situation 190 shows that besides considering social benefits, researchers and schools still need to consider the quantity of the scientific research without considering the quality of the scientific research. Currently the status of university research evaluation is the stable situation 190. The equilibrium of the situation 73 shows only considering the quality of the scientific research, researchers, schools and government can reach the equilibrium.

From the above analysis, we know that the situation 255 is the Pareto of evaluation system of university scientific achievements, and the situation 190 mostly conforms the equilibrium status of university research evaluation. To make the conflict equilibrium situation of university research evaluation system turn the situation 91, 190 and 73 to the situation 255, scientific researchers, schools and government must constantly improve and perfectly develop the important role of the evaluation system in practice.

\section{Acknowledgments}

This papaert is financially supported by the National Natural Science Foundation of China(71002046) ; Post doctoral degrees funds of China and Jiangsu province (NO: 20100481135, 1001051C);Jiangsu Social Science Foundation (11GLA003) and Basic scientific research expenses special research project of Nanjing University of Aeronautics and Astronautics (NJ20120011).

\section{REFERENCES}

Zhang Wei. Frequently Met Problems in Evaluation on Scientific Reaearch in Higher Educational Institutions and Innovation of Evaluation System [J]. Journal of Taiyuan Normal University(SOCIAL SCIENCES EDITION),2007,(04).

Ceng Yuqing. Evaluation method and application of university research outputs [J]. Hunan social science, 2006,(04).

Zhou Ying, Wang Pusheng.Conflict of interests in peer review, analysis and treatment [J].Science research. 2003,(03).

Deng Yi. Quantitative evaluation of scientific research in universities [J].Modern education, 2006,48(4).

Qiu Junping, Tan Chunhui. Significances, System and Practices of Evaluation of Humanities and Social Science in China [J]. Journal of Chongqing University(SOCIAL SCIENCES EDITION), 2007,(05). 